\title{
Herpetofauna Diversity and Taxa Richness Ground Cover Plant as Bioindicator Environmental Quality in Boon Pring Recreation sites at Sanankerto, Turen, Malang Regency
}

\author{
Wahyu Anggarwanto*, Endang Arisoesilaningsih \\ Department of Biology, Faculty of Mathematics and Natural Sciences, University of Brawijaya, Malang, Indonesia
}

\begin{abstract}
Boon Pring is one of the ecotourism destinations in Malang regency with tourism attractions including motor boats, water bikes, and picnic activities. These activities can cause environmental degradation in Boon Pring area. The purpose of this research is to analyze taxa richness of ground cover plant, diversity, and community structure of herpetofauna in Boon Pring and explain the environmental quality in Boon Pring based on their relationship. The method used is selective purposive belt transect with $10 \mathrm{~m}$ long belt and $10 \times 5 \mathrm{~m}^{2}$ plot area. Each station is repeated four times. The data obtained were analyzed with Ms. Excel and the PAST program to search Taxa Richness for plants, abundance, frequency, Shannon - Wiener diversity index and Import Value Index (IVI) for Herpetofauna. Then they were analyzed regression, cluster, and biplot to determine the relationship between the two. The results showed decreased of ground cover plants taxa richness and herpetofauna diversity index from station one to station four. The value of IVI indicates the dominance of Eutrophis multifasciuata species in degraded sites. Determination coefficient showed a value of 51\%, which means there is a positive relationship between ground cover plant and herpetofauna diversity. The conclusions of this study, the taxa richness of ground cover and diversity of herpetofauna have decreased in areas with degraded environmental quality. There is a dominance of one type of herpetofauna in the degraded areas of Eutrophis multifasciuata. Between the taxa richness of ground cover plants and diversity of herpetofauna showed a positive relationship, in this study $51 \%$.
\end{abstract}

Keywords: Boon Pring, Diversity Index, Ground Cover Plant, Herpetofauna, Regression.

\section{INTRODUCTION}

Ecotourism in Malang Regency increasingly growing. One of the newly-opened ecotourism in 2016 is Boon Pring Andeman in Sanankerto Village, Turen, Malang regency. Before it becomes a tourism interest, this location was a bamboo forest with about 60 species richness kinds of bamboo. Tourist attractions in Boon Pring are emphasized on Boon Pring lake. This lake is used by tourists to play water bikes and rent a motorboat in purpose to go around the lake. In addition, Boon Pring also has picnic areas and swimming pools which are widely utilized as family vacation [1].

The human activity in Boon Pring shows an increment every day. The number of tourists who visit this place keeps increasing every day. It makes the manager improve Boon Pring's service facilities and infrastructure. The improvement of these facilities and infrastructure can reduce the naturalness of Boon Pring as a bamboo forest. The reduced levels of naturalness mean environmental degradation growth is raising in

\footnotetext{
*Correspondence address:

Wahyu Anggarwanto

Email : wahyuanggarwanto@yahoo.co.id

Address : Dept of Biology, University of Brawijaya, Veteran Malang, Malang 65145
}

Boon Pring. This matter should be studied in order to know how much the degradation impact on the environment. One way to learn about environmental degradation is by using bioindicator. Bioindicators themselves means an indicator or a sign based on the existence of a living being [2].

There are so many bioindicators in nature ranging from microorganisms to vertebrates. For instance, ground cover plants and herpetofauna are organisms that are included in bioindicators. Ground cover plants have a high degree of sensitivity to environmental changes. It is because ground cover plants are pioneer organisms that will form microhabitats for animals and plants with habitus above them. Their essential role which is to raise nitrogen binding in the soil becomes the main underlying factor to decide that ground cover plants can be used as bioindicator [3].

Not only ground cover plants, herpetofauna community is also able to be applied as a bioindicator. Herpetofauna or groups of reptile and amphibian animals are a type of vertebrate that is sensitive to environmental degradation. The sensitive amphibious animal and reptile senses become the underlying factor to include herpetofauna as one of the bioindicators. 
Poikilotherm animals are also included as herpetofauna due to its environment-dependent body temperature. If the environment is not suitable for them, herpetofauna will not be able to live in the corresponding environment [4].

The Boon Pring environment is a suitable environment for herpetofauna. The existence of lakes and bamboo forests increases the humidity of the environment and makes it a suitable place for herpetofauna. Therefore, the environmental quality measurement at Boon Pring can utilize herpetofauna as bioindicator. Besides the diversity of herpetofauna, ground cover plant taxa richness was used to complete the environmental quality assessment in Boon Pring. This study aimed to analyze the ground cover plant taxa richness, herpetofauna diversity, and community structure. Moreover, this study also projected to the environment based on their relationship.

\section{RESEARCH METHODS \\ Sampling Methods}

This research was conducted at Boon Pring Andeman, Sanankerto Village, Turen, Malang Regency $-8.155802 \mathrm{~S}$ and $112.761982 \mathrm{E}$. This research was conducted from November to December 2017. Sampling was conducted at four stations (Fig. 1), bamboo forest, bamboomahogany forest, tourist area, and mahogany garden. The applied method was selective purposive belt transect. Each location sampled four times by using selective purposive belt transect with $10 \mathrm{~m}$ long belt and $10 \times 5 \mathrm{~m}^{2}$ plot area (Fig. 2) to obtain the results that represent the station. In addition, in this study researcher get data from an interview with local people.

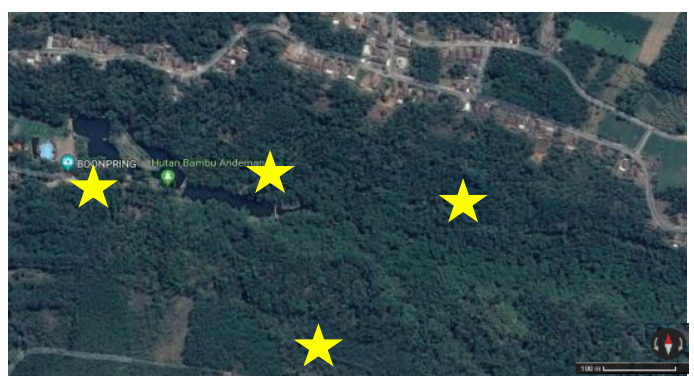

Figure 1. Four Sampling Location in Boon Pring Andeman

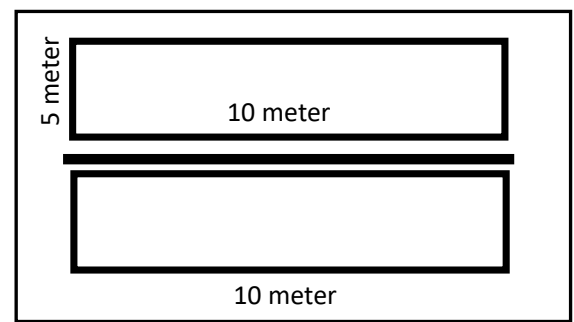

Figure 2. Selective Purposive Belt Transect Design

\section{Data Analyze}

Ground cover plant data was analyzed by Ms. Excel 2007 to found its taxa richness. Herpetofauna data was analyzed for abundance, frequency, relative abundance, relative frequency, Important Value Index (IVI) and Shanon - Wiener Diversity Index $\left(\mathrm{H}^{\prime}\right)$ which is also analyzed using Ms. Excel 2007. PAST Program was used for analyzing its regression, cluster, and biplot.

\section{RESULT AND DISCUSSION}

The results showed a positive relationship between taxa richness of ground cover plants with the Herpetofauna Shannon - Wiener diversity index (Fig. 3). The highest value for taxa richness of ground cover plants and Herpetofauna Shannon - Wiener diversity index is located in the bamboo forest location. The taxa richness value of ground cover plants in bamboo forest reaches 15 taxa while herpetofauna Shannon - Wiener diversity index is 0.6. Based on the journal [5], bamboo forest is a habitat of some herpetofauna such as snakes, frogs, and toads. This is due to the shade of bamboo headers are causing the microhabitat becomes more humid and suitable for herpetofauna habitat that likes more humid places. Besides that, bamboo forests provide many leaves litter for many small insects that become the main food of frogs and toads.

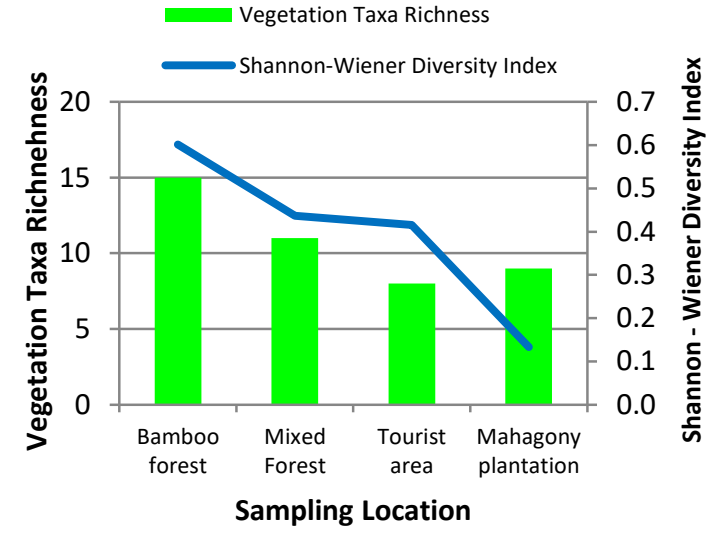

Figure 3. Correlation graph between ground cover taxa richness and herpetofauna Shannon - Wiener diversity index

From the study, it is elicited unique data. The location of the mahogany garden has a very low value of herpetofauna Shannon - Wiener diversity index (0.1) but has a slightly higher taxa richness of ground cover ( 9 taxa) than the tourist area ( 8 taxa). It is because mahogany is included as exotic species. Mahogany (Swietenia mahogany) is a type of tree that is widely used 
for its daily needs. This exotic species is included as a species that has a huge amount of waterwaste (water-waster). Water-waster means it requires a lot of water to make it grow well. So, this plant will absorb water around it to the maximum extent that this plant can absorb [6]. This condition causes the situation of microhabitat around mahogany is dry. So that herpetofauna cannot live comfortably. However, some plants can survive with little water supply. The condition of mixed bamboo - mahogany forest is not like the mahogany garden. Bamboo is a good provider of water and storage [5]. Thus, the microhabitat under the canopy can still be maintained and create a suitable microclimate for herpetofauna and ground cover plants.

Taxa richness of ground cover plants on tourist area or it can be said that degraded areas have low value. Although it has higher diversity value of herpetofauna than mahogany forest. The location of tourist area is dominated by Eutrophis multifasciuata. This is indicated by the high value of the Importance Value Index (IVI) in the tourist area (Fig.4).

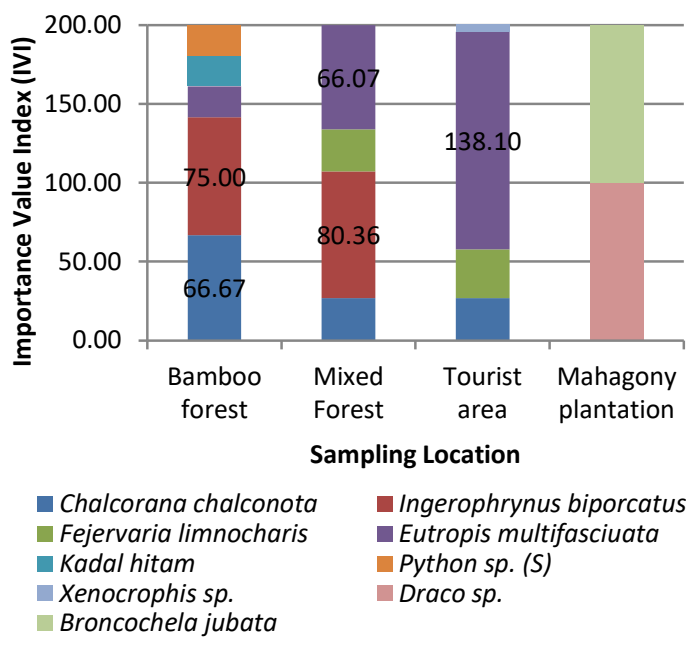

Figure 4. Importance Value Index (IVI) of each species that found in Boon Pring. (S) indicate secondary data

Eutrophic multifasciuata or garden lizards or Common Sun Skink is known as the most commonly found lizard in areas that are already open or have few canopies. The existence of this lizard may indicate that the site is already degraded because it is a cosmopolitan animal and is able to survive in areas where it has no canopy protection [7]. One of the indications of the degraded environment is the reduced or the loss of plant canopy like in Boon Pring tourist area. There is no dominance of any species herpetofauna in other sampling location.
The result of regression analysis shows that there is a relationship between cover plants and herpetofauna. The coefficient of determination on the regression analysis reaches 51\% (Fig. 5). The value of determination coefficient here shows how much taxa richness effect of ground cover plants on herpetofauna diversity in Boon Pring. The value of $51 \%$, indicating the influence of taxa richness has a significant effect on the diversity of herpetofauna. Herpetofauna has a fairly narrow microhabitat in nature, the existence of herpetofauna must be supported by good environmental conditions in order to support the survival of herpetofauna. One thing that made microhabitat suitable with the environmental conditions for herpetofauna is the ground cover plants. Ground cover plants can provide protection for herpetofauna. In addition, the presence of flowers in ground cover plants will provide prey to herpetofauna [4].

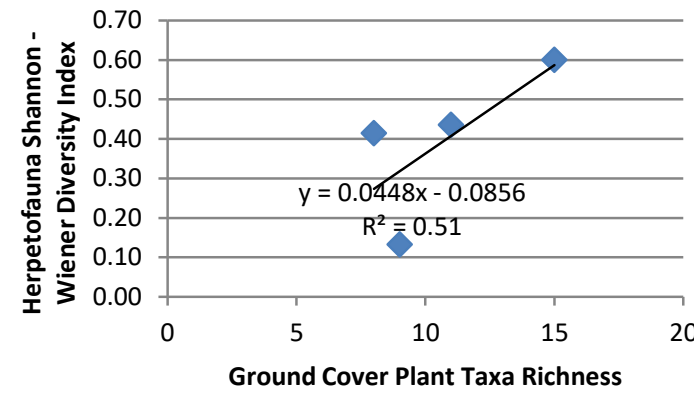

Figure 5. Regression analyze between Ground Cover Plant Taxa Richness and Herpetofauna Shannon - Wiener Diversity Index

Cluster and biplot analysis are used to classify locations based on the factors affecting the location. The result of cluster analysis with distance $50 \%$ similarity level shows three different location groups. These groups are mahogany garden, mixed forest, and tourist areas groups and bamboo forest groups (Fig. 6). Each location is characterized by a few specific things. This is demonstrated by biplot analysis (Fig. 7). The mahogany garden group is characterized by its low herpetofauna diversity and the co-domination of Draco $s p$. and Broncochela jubata. Mixed forest and tourist areas groups are characterized as having low ground cover plant taxa richness and have some herpetofauna that can withstand the environmental changes. While the bamboo forest group is characterized by the diversity of herpetofauna and taxa richness of high ground cover plants and has herpetofauna which more sensitive to environmental changes. 


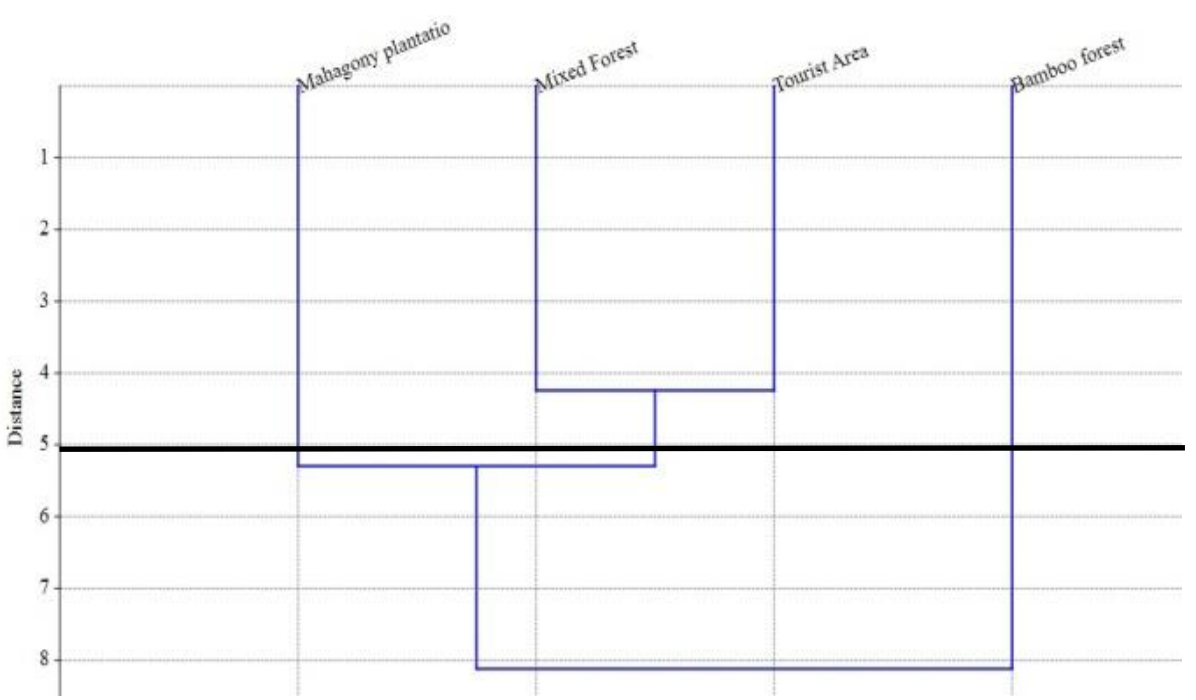

Figure 6. Cluster analysis of each location in Boon Pring

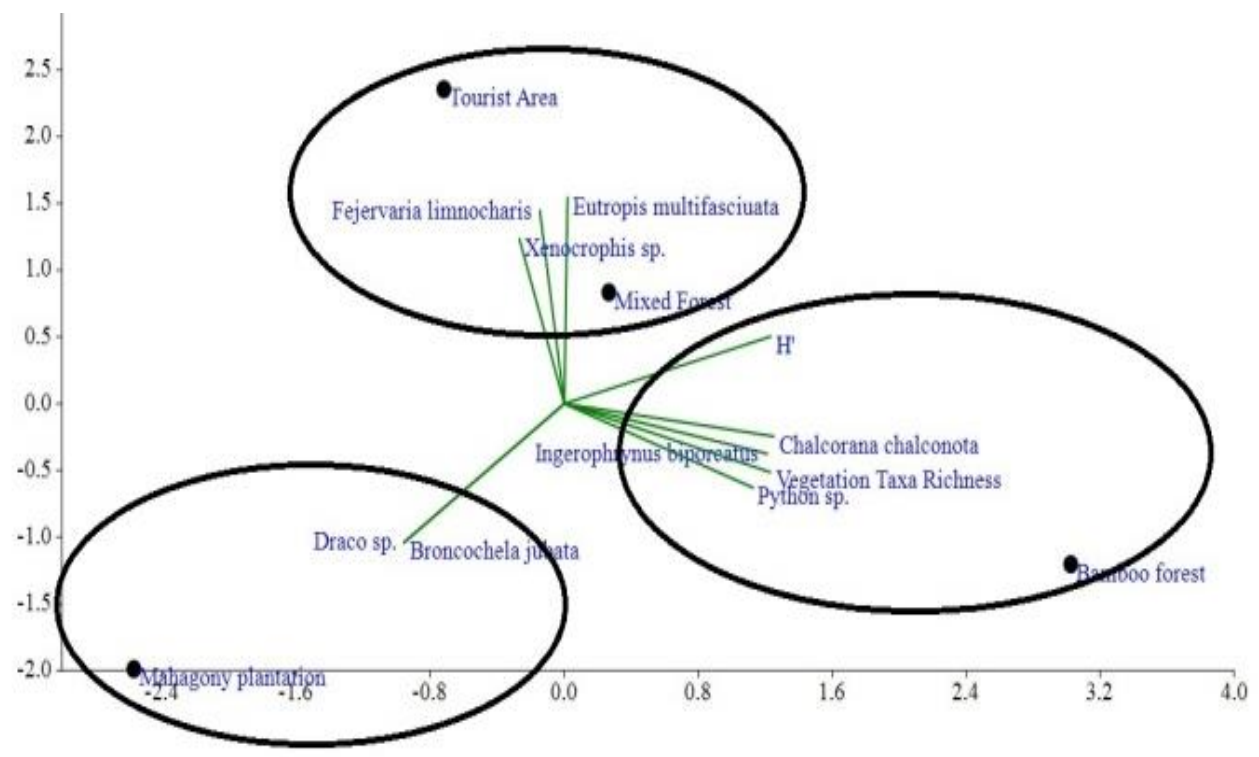

Figure 7. Biplot analysis for each location in Boon Pring

After conducting this research, researchers should advise managers not to plant many invasive plants at the Boonpring site. This suggestion is to keep the herpetofauna habitat that is not disturbed and remain stable.

\section{CONCLUSION}

This research concludes that all ground cover plant taxa richness and herpetofauna diversity was decreased from bamboo forest to the tourist area. There is a dominance of E. multifasciuata in degraded land (tourist area). Study about $E$. multifasciuata as a bioindicator can be done for the other research. There was a positive relationship between ground cover plant taxa richness and herpetofauna diversity. The more degraded the land or the lower taxa richness ground cover plant the less herpetofauna diversity will be. So, from this study, we might know that degraded land does not increase any biological aspect.

\section{ACKNOWLEDGEMENT}

This research is supported by Ecology and Animal Diversity Laboratory of Brawijaya University and Boon Pring Andeman Tourism. Authors would like to thank all of the author's friends and Mr. Purnomo in assisstingthe author sampling in field. 


\section{REFERENCES}

[1] Aminudin, M. Yang baru di Malang, Ekowisata Boon Pring. Available at: https://travel.detik.com/domesticdestination/d-3458964/yang-baru-dimalang-ekowisata-boon-pring

[2] Kurniati H. 2007. The herpetofauna of the gold mining in project area in North Sumatra: Species richness before exploitation activities. Zoo Indonesia 16 (1), 1-11.

[3] Meza-Parral, Y. and E. Pineda. 2015. Amphibian diversity and threatened species in a severely transformed neotropical region in Mexico. PLoS ONE 10(3), 1-14.

[4] Haacke, W. D. 2009. Herpetofauna habitat assessment of Mokolo - Crocodile river water pipeline. Herpetofauna Report: Mokolo Phase 1, 1-14.

[5] Arinasa, Ida B. K. 2005. Keanekaragaman dan penggunaan jenis-jenis bambu di Desa Tigawasa, Bali. Biodiversitas 6(1), 17-21.

[6] Majid, M. A., I. M. M. Rahman, M. A. H. Shipar, M. H. Uddin and R. Chowdhury. 2004. Physico-chemical characterization, antimicrobial activity and toxicity analysis of Swietenia mahagoni seed oil. International Journal of Agriculture and Biology 6(2), 350354.

[7] Ji, X., L. H. Lin, C. X. Lin, Q. B. Qiu and Y. Du. 2006. Sexual dimorphism and female reproduction in the Many-Lined Sun Skink (Mabuya multifasciata) from China. Journal of Herpetology 40(3), 351-357. 